\title{
ENTREVISTA A MONSEÑOR LINO PANIZZA
}

\section{José Antonio Benito*}

$1 \begin{aligned} & \text { onseñor Lino Panizza, Obispo de Carabayllo, fundador y Gran } \\ & \text { Canciller de la UCSS, fue entrevistado }{ }^{1} \text { por José Antonio Benito. } \\ & \text { Monseñor narra algunos episodios muy interesantes de su vida: su }\end{aligned}$ llegada al Perú, su trabajo en la pastoral educativa, sus inicios en la Diócesis de Carabayllo, su desempeño en Cáritas del Perú, sus vivencias en Arequipa y el inicio de la Universidad Católica Sedes Sapientiae.

-Monseñor, dicen que los cargos son los que traen cargas. ¿Cuál fue su reacción cuando sus compañeros del episcopado lo eligieron?, ¿qué siente?, ¿cómo lo está afrontando?

—Las palabras que yo pronuncié cuando salió el resultado de la votación, estuvieron dirigidas al mismo obispo: «Le perdono por el mal que me quiere». Esas fueron mis palabras, pues realmente no lo esperaba. Cuando se estaba

Director del Centro de Estudios para el Patrimonio Cultural de la UCSS.

1 Entrevista realizada en PAX TV cuando Monseñor Lino Panizza desempeñaba el cargo de Secretario General de la Conferencia Episcopal Peruana para el nuevo trienio. 
JOSÉ ANTONIO BENITO

voceando mi candidatura, la cual no presenté, se manejaba esa posibilidad. No se trata de que uno no quiera cargar con una responsabilidad, con un servicio. Después de haber estado seis años a la cabeza de Cáritas del Perú, sentía la necesidad de dedicarme más a la diócesis que el Señor me había confiado (Diócesis de Carabayllo) con todas las obras que faltan por hacer; pues la había descuidado un poco. Entonces, quería recuperar el terreno perdido. Después de un poco más de un año, el Señor me comprometió con este nuevo servicio. El Señor lo da, el Señor lo quita. ¡Gloria a Dios! Estoy agradecido con Dios por la posibilidad que me brinda de servirle y nada más.

- Son varios frentes ahora: catequesis familiar, la Universidad Católica Sedes Sapientiae, la diócesis y ahora este nuevo cargo.

- Sí, los frentes son varios. Creo que si me esfuerzo en tener fe en el Señor, sería una prueba para confiar más en Él. Si pienso en mis cualidades y mis posibilidades, veo difícil que pueda realizar todo esto. Pero es cierto que quien actúa es el Señor. Tengo la plena seguridad de que trataré de hacerlo posible; es decir, me esforzaré por cumplir las metas poniendo todo el empeño para que salgan de la mejor manera. El resultado está en manos de Dios; el resultado no depende de mí. Yo siembro, yo riego. La cosecha la dejamos para que Dios la haga.

- Monseñor, acabo de venir con usted de la Conferencia Episcopal Peruana y he comprobado lo de siempre: tanto en la diócesis como en la universidad, se siente el espiritu de familia y lo a gusto que se puede estar con su compañia. Estamos con nuestro padre en la casa y, por eso, me gustaría que hablase un poco acerca de dónde nació y cómo fue su formación. 
—Nunca pensé realmente sobre cuál era el origen de ese espíritu de apertura y acogida que siento. Al escuchar su pregunta, es la primera vez que me lo cuestiono. Creo que una de la causas de esta cualidad, de este don, de esta gracia que el Señor me concedió se debe a que mi casa siempre fue una casa abierta. Soy hijo de campesinos. Nací en un pueblo pequeño en el campo del norte de Italia, en el camino entre Génova y la frontera con Francia. Es un pueblito chico; ahí la vida es dura. No hay grandes extensiones de tierra; pero sí una vida feliz. Recuerdo que mi casa siempre estaba abierta. Cuando asistía al Seminario e iba de paseo con amigos y pasábamos por mi casa, entrábamos. Mi papá recibía a todos y mi mamá sacaba de donde sea algo para servir a cada uno de los que ingresaban; eso me gustó. Por otro lado, lo que también me condujo a esta dimensión fue peregrinar por el mundo y pasar por diferentes oficios, tareas y servicios. He descubierto lo importante que es la hospitalidad. Llegar a un lugar desconocido, cuyo idioma no entiendes, y que alguien te abra la puerta y te diga que esa también es tu casa es realmente algo maravilloso. Por eso, me he propuesto hacer lo mismo con todos aquellos que se acerquen a mi casa para que se sientan bien.

— ¿Cuándo comenzó esa peregrinación? ¿Cuándo salió de Italia?

- La primera vez que salí fuera de Italia fue para estudiar en España, en Madrid específicamente, a finales de 1969. Ya era sacerdote. Fui ahí a estudiar y ahí comencé a experimentar el don de la hospitalidad, de esa apertura que me hizo sentir bien; y eso que me habían prevenido sobre la poca hospitalidad de los madrileños. Sin embargo, siempre di testimonio de todo lo contrario, puesto que me acogieron con una hospitalidad extraordinaria. Me decía: «Cuando tenga la oportunidad, yo haré lo mismo». 
-Y aqui al Perú, ¿cuándo llegó?

—En el año 70. Llegué una semana antes que el padre Roberto, fundador de este canal. Él también llegó por esos años por el terremoto. Nos encontramos y trabajamos juntos durante el 71 y 72 . Él era Capellán del hospital San Juan de Dios, donde comenzó a trabajar desde que llegó. Tenía los cursillos de Cristiandad. Trabajábamos juntos en los cursillos. Él realizaba los famosos retiros con el personal auxiliar médico del hospital; los llevaba a Ricardo Palma en Santa Eulalia, donde estaban los Hermanos Maristas. Ahí, yo iba a ayudar a confesar. Fue una experiencia de vida muy bonita.

-Ya han pasado 38 años. ¿Vino aqui directo a Lima?, ¿a qué parroquia?

—Vine a Lima y fui inicialmente a Chorrillos por causa del terremoto. Llegué una semana antes de que ocurriera el terremoto de Huaraz. Me dediqué a apoyar a los damnificados. Después, en el mes de septiembre u octubre, fui a Tingo María para reemplazar al párroco, quien tenía que ser operado. Él era franciscano y tenía que ir a Canadá. Estuve en Tingo María hasta el mes de febrero o marzo en el año 71. Luego fui designado a la parroquia Cristo Salvador en Chama.

—Y ahi estuvo involucrado también en lo educativo, lo pastoral... hizo muchas amistades, conoció muchas familias...

-Bueno, ahí en Chama, en Cristo Salvador, estuve en dos momentos: desde el año 71, luego me fui a Arequipa y regresé en el año 80. Ahí tuve la experiencia de ser director del colegio parroquial. En aquella época, solo había una casa alrededor. No había nada, ni Higuereta, ni Vista Alegre; todos los alrededores eran haciendas. Recuerdo que fui a celebrar una fiesta en la hacienda San Juan Grande y San Juan Chico. Ahí comenzamos a construir la comunidad parroquial, la comunidad eclesial. Empecé con seis hombres 
que recluté con una «tallarinada», pues era lo único que sabía hacer. Así se inició la gran aventura. Hubo mucho empuje en lo pastoral y, gracias a Dios, ha continuado y sigue todavía.

- Hicimos un viaje, pero volvimos enseguida de Arequipa. Regresemos para que nos cuente acerca de la parroquia de los Padres Capuchinos en Umacollo, donde se ven decenas de jóvenes, además de numerosos frailes.

—Fui a Arequipa en el año 1977 como párroco. Estaba solo en Umacollo. No había mucha gente y la parroquia estaba casi «muerta». En el arzobispado de Arequipa, se encontraba Monseñor Rodríguez Ballón y Monseñor Unfrield, quienes trataban de dar un impulso pastoral tradicional. Entonces hicimos, en la parroquia de los Capuchinos, una serie de experiencias pastorales. Iniciamos los encuentros con los jóvenes EPJ. Se trataba de mover a los jóvenes con los EPJ (Encuentros de Promoción Juvenil). Comenzamos un día de fiestas patrias; llevé un equipo de Lima hasta allá. Antes de ir a Arequipa, ya había vivido en Lima. Había trabajado con el Encuentro Matrimonial y fue una experiencia que me marcó mucho. Estuve en Chama, luego fui a vivir a la Planicie, en Chaclacayo. Viví la experiencia y me gustó. Estando ahí, en el trabajo parroquial, vi que era importante la pastoral familiar; entonces invité a mis amigos de Lima para que fueran a Arequipa e iniciamos los encuentros matrimoniales. Además, nacieron otros encuentros como los Talleres de Oración y Vida del Padre Larrañaga, Escoge, Ene, Cristóforos: todos los movimientos que han dinamizado la pastoral. Luego, antes de retirarme, había preparado la experiencia del Camino Neocatecumenal de la parroquia — que ahora tiene mucha vitalidad—. Fueron años muy hermosos, muy bonitos, de gran vitalidad y con mucha entrega por parte de los laicos y de todos los católicos. 
JOSÉ ANTONIO BENITO

- ¿Tantas vocaciones tienen algo que ver con esa revitalización entre los jóvenes? -Yo creo que sí. Ahora, como obispo, desde otra realidad, me doy cuenta de que las vocaciones surgen desde donde se trabaja, donde hay vitalidad espiritual, donde el sacerdote cree en su sacerdocio. Creer en el propio sacerdocio se manifiesta en el entusiasmo con el cual uno se entrega al trabajo con los jóvenes, los ancianos, los adultos, las parejas, con toda la realidad; ahí es donde los jóvenes se enamoran. Es decir, la vocación nace cuando uno va saboreando qué significa tener a Dios en la vida; este Dios debe ser compartido y no retenido para sí mismo.

\section{—_Cuándo comenzó esa experiencia para usted, Monseñor?}

- Mi vocación es de las más ordinarias que hay. No es como la de san Pablo, a quien Cristo se le apareció y lo tumbó del caballo, nada por el estilo. Nace desde una familia de fe. Recuerdo que de niño fui acólito, me despertaba e iba a la misa. Ese fue el primer paso: acolitar. Luego vino el acompañamiento del párroco, quien hizo despertar esa vocación. Después recuerdo las visitas que hacían los hermanos limosneros de los Padres Capuchinos a mi pueblo, quienes pasaban a recoger las primicias, esto decir, la primera cosecha de los olivos, de la uva, del trigo, etc. La gente daba estas primicias como diezmo a los limosneros que pasaban. Después, venían los misioneros a contarnos las aventuras de las misiones, la obra que hacia la Iglesia en la misión; esto a uno lo enamora, y de niño quieres imitarlo. Además, mi papá iba a ayudar en la chacra del Seminario para mantener el jardín. Nosotros éramos pobres, hicimos la secundaria en el colegio de los Capuchinos; allí es en donde fue madurando mi vocación hasta que tomé la decisión de ingresar a la Orden, hacer el postulantado, el noviciado, etc. Así fue hasta que tomé la decisión de decir: «Sí, yo quiero ser del Señor, dar mi vida al Señor, a los hermanos», así de simple. Ha sido un proceso. 
- Háblenos ahora como pastor. Como siempre dicen que la niña de los ojos del pastor es su Seminario. El fomento de las vocaciones nos habla un poco de cómo ha ido potenciando a los grupos. ¿Qué es lo que ahora está trabajando como pastor?

-No cuido el Seminario, porque no lo tengo. Sin embargo, tengo seminaristas que realmente cuidamos como «a la niña de los ojos» de la diócesis. Tenemos seminaristas en distintos lugares: en Trujillo, Callao, Arequipa y en la Diócesis. Aquí tenemos un preseminario en la parroquia Santísimo Sacramento con el padre Raúl Cornejo y el padre Pedro, quienes trabajan un año de preparación para ingresar al Seminario. Después los mandamos a Arequipa, Trujillo y al Callao. Durante el verano, hacemos el trabajo para unificarlos, para hacer que se conozcan; entonces tenemos una especie de Seminario en la Diócesis. Realmente debemos dar gracias a Dios, pues este año hemos tenido 56 seminaristas; el próximo año vamos a pasar los 60 .

\section{— ¿De dónde vienen?}

—De la parroquia y los movimientos. Dios llama donde quiere y como quiere. La provisión es un buen número.

—De todas maneras, Carabayllo es una diócesis gigante, pero la relación entre los sacerdotes y los fieles todavía es muy escasa, ¿no?

—La diócesis, como territorio, no es exagerada. En una hora y media o dos se puede ir de un extremo a otro. La población es muchísima, se calcula entre dos millones a dos millones y medio en el censo último. Saber el número exacto es muy complicado, muy difícil. Los sacerdotes que trabajan pastoralmente son del clero diocesano; los religiosos, los misioneros, los fidedignos son más de 80 . 
JOSÉ ANTONIO BENITO

- ¿Son 12 años o algo asi?

—Este año, el 2 de febrero se cumplirán 11 años de inicio de la vida diocesana.

-Y hablando de la Diócesis, porque es una nueva realidad, supongo que ha sido una gracia bien grande y también una responsabilidad muy fuerte. Es como pasar de la nada a crear algo. Creo que antes habia obispos auxiliares o vicarios que atendian; pero hay cosas todavía que están por crearse: la catedral, el seminario... ¿Qué nos podría decir sobre los primeros momentos de la Diócesis y cómo lo está viviendo?

- Sí, antes había la arquidiócesis de Lima, que estaba dividida en vicarías. Esa zona era la vicaría 1. En el Cono Norte, había un obispo encargado, un vicario que coordinaba la pastoral y las actividades; pero no encontré nada. Entonces tuvimos que comenzar a crear un centro, las oficinas, la curia; es decir, nos preocupamos por hacer. Luego tendríamos que hacer la catedral, porque no la tenemos, y el Seminario, que tampoco tenemos.

— ¿Dónde estaría la catedral? ¿Tiene algún lugar?

- Hay varios lugares. Estamos viendo cómo conseguir el terreno.

—Escuché una anécdota del cardenal Gantín, quien vino y me dijo: "Esta es nuestra catedral».

—Exacto. En la bula de la creación de la diócesis, el Santo Padre designó una catedral, que es la parroquia de Nuestra Señora de la Luz en Santa Luzmila; pero no había iglesia, como no hay todavía. Existe la parroquia, pero sin templo; por ello, el Nuncio me dijo: «Monseñor tiene que llevarlo a conocer la catedral». — «Pero, excelencia, no hay catedral». Entonces me dijo: «¡No puede ser! ¡Tiene que haber catedral!, porque no hay diócesis sin catedral». Bueno, hay un galpón con 4 palos y techo de calaminas: eso es 
la catedral. Tenía vergüenza de no enseñarles nada, pero fue muy bonito. Cuando llegamos, había una señora anciana colgada de esa grada; encima del pedestal había un sagrario de madera. Esta señora estaba colgada al sagrario llorando. El cardenal se acercó a ella y le hablo; no sé si se habían entendido o no, porque estuvo hablando un ratito con ella y luego nos fuimos. No hizo ningún comentario sobre la catedral. Es como decir: «Yo creo que la catedral está donde está el Señor, la presencia del Señor, la presencia de Dios».

—En esta línea, su capilla personal también me ha impresionado. Esa cruz que brota como un árbol, un árbol de la vida. Estamos hablando de que meterse en el corazón de la Iglesia, también es meterse en un mundo para entregarse a Él. He visto, además, el guante del padre Pío. ¿Qué nos puede decir ese corazoncito de la Diócesis?

-Cuando pensé hacer la Casa Episcopal — porque tampoco tenemos casa, el obispo no tenía casa, ni oficina. Ahí había un rincón forrado de plástico que funcionaba como cocina. Cuando comenzamos a reordenar la casa, sacamos el plástico y descubrimos que estaba enchapada en madera. Habían tapado la madera con plástico; era una madera muy bonita. Entonces, en un rincón de la casa, dije: "Ahí voy a hacer la capilla». Tuve la idea de la capilla recordando la sagrada escritura: « QQuítate los zapatos; este es un lugar santo!». La capilla es un lugar santo; por eso, hay que entrar a pie descalzo al encuentro con el Señor. Luego dije: «Si no hay una zarza ardiendo, tengo que buscar un árbol que tenga la forma de zarza». Me demoré un año y no conseguí el árbol, uno que me gustara. Cuando hubo una exposición sobre los Chacas, vi ese enorme árbol, que era el doble o triple de lo que es ahora, y dije: «La punta en donde está el crucifijo me sirve a mí». Y variando la idea dije: «No, en el árbol de la cruz llegó la salvación del mundo; entonces detrás está el fuego que arde y delante está el árbol en donde está colgado el 
Cristo de la salvación del mundo, y a los pies está la Virgen como Madre que nos entrega a nosotros». Este era el sentido de la capilla: orar y adorar con la finalidad de que el obispo pueda ir también a orar.

El «guante del padre Pío» tiene otra historia. Yo tenía un amigo párroco en Florencia, a quien siempre visitaba. Ahí conocí a un señor que me dijo: «Padre, queremos hacerlo miembro del grupo de oración del padre Pío». — «Yo con mucho gusto — contesté—, pero estoy en el Perú. De Florencia a Lima hay un abismo, un mar, un océano». — «No importa, la oración nos une. Nosotros le escribimos. Usted es miembro de nuestro grupo». Y así siempre hemos estado unidos. Cuando voy a Italia, si puedo, voy a visitar a este sacerdote amigo. El año pasado en la fiesta de la Asunción, me dijo: «Padre, nuestro amigo Paineider, cuando murió, me dejó esto y me dijo: "Don, yo me voy a morir, y antes de que esta reliquia se pierda, se la entrego a usted; porque no sé qué va a ser de ella. Entonces, usted me la va a cuidar”. Y me entregó ese cuadro con el guante del padre Pío». El año pasado, cuando estábamos ahí conversando, me dijo: «Yo también tengo mi edad y no sé a dónde me mandará el Arzobispo; mejor esto usted se lo lleva y lo pone en una iglesia». Yo le dije: «Pues, lo que sea. ¡Bienvenido! Está buena la reliquia, muchas gracias». El padre Pío es quien ha hecho el milagro de la casa del obispado, así que yo lo he puesto ahí.

\section{- El milagro del padre Pío en el obispado de Carabayllo.}

-Cuando crearon la diócesis y me nombraron obispo, fui a ver el territorio. No tenía casa, no tenía catedral, no tenía seminario, no tenía nada. Yo seguía viviendo porque me acogieron en la parroquia de Chorrillos durante año y medio, casi dos años, e iba todos los días desde Chorrillos hasta la diócesis en carro. En mi carro tenía sellos. Ahí se encontraba mi oficina portátil, pues atendía a la gente y sellaba los documentos, mientras estábamos buscando un lugar donde poner la sede. Esto fune providencial, porque hizo que yo 
conociera la diócesis. Entonces eso para mí fue providencial, porque yo no conocía en absoluto el Cono Norte. He estado como ambulante con mi carro-oficina. Mientras buscábamos un lugar, el párroco de Sol de Oro nos dijo que había una casa en venta. — «Cuánto piden?». — «130 000 o 140000 dólares». Yo dije: "Yo no tengo. Busquemos una más barata». Y continuamos buscando hasta que un día la dueña de esta casa vino a buscarnos para vendérnosla. Era hipotecada. Si no levantaba la hipoteca, perdía todo.

Entonces me dijo: «Ustedes me dan 30000 dólares para levantar la hipoteca y el resto me pagan cuando quieran». Entonces le dije al padre Pedro: «Podemos ofrecerle 70000 dólares». Y le dijimos: «Señora, le damos 30 000». Cuando me hicieron obispo, amigos e instituciones me regalaban cosas; pero mi secretaria inteligentemente les dijo: «No le den nada que no necesita nada, no necesita gran cosa para vestirse ni casa; regálenle plata». Con eso reuní 35000 dólares; los tenía guardaditos. Cuando vine le dije: «Padre Pedro, yo tengo 30000 dólares. Levantaremos la hipoteca y le daremos 20000 a fin de año, y el año siguiente otros 20 000». Y quedamos así. A fin de año, el padre Pedro dijo: «No. El colegio, que nunca ha dado nada a la Iglesia, tiene un fondo; podemos sacar 20000 para pagar esto». Luego, al año siguiente, pagaremos la cuota final.

Durante todo el año —año y medio exactamente- hicimos trabajitos para levantar la casa, porque lógicamente una casa cerrada cuesta plata. Prácticamente todas las donaciones que venían las invertíamos en la casa, que nos costó mucho más de lo que creíamos. Casa vieja siempre es un desastre. Cuando llegó la hora de pagar la última cuota, el padre Pedro me dijo: «Monseñor, tenemos que pagar 20000 dólares». Le dije: «¿Tú los tienes?». — «No, yo no los tengo» — me contestó—. El padre Pedro me dijo: «Haremos un préstamo, antes de que suceda lo que a la señora; es decir, antes 
de que no tengamos para pagar y nos quiten la casa». Cuando llegué a la casa de Chorrillos en la noche, a las 10:00 u 11:00 de la noche, encontré un aviso que decía: «Padre, le llamó fulano y dejó un teléfono». Esto pasó durante tres noches; yo no podía llamar porque salía a las 6:00 de la mañana de la casa y llegaba 10:00 u 11:00 de la noche, y me daba vergüenza, me parecía incorrecto molestar a esa hora. Hasta que lo llamé el día 29 para ponerme a su disposición, para ver lo que necesitaba. Coordinamos en encontrarnos en la oficina de catequesis de la Conferencia Episcopal el 30 o 31. Él vino y yo recibí un milagro: estaba en un consultorio donde había una revista del padre Pío; mientras esperaba, me encomendé a este hombre - que no era santo todavía- y me hizo el milagro. He hecho una promesa y vengo a cumplir con la promesa, me dijo. Entonces pregunté: «Yo a usted no lo conozco, ¿por qué cumple la promesa conmigo?, ¿qué tengo que ver yo?, ¿por qué su nombre está en la revista?». De pronto, me entregó un sobre. Nos saludamos y se fue. Me dio curiosidad y abrí el sobre... había 20000 dólares, ni uno más, ni uno menos. Entonces le dije al padre Pedro: «Aquí hay 20000 dólares para pagar la casa. Ese es el don del padre Pío».

- Bendito padre Pio y bendita Divina Providencia. -Así es.

- Y con esto podemos comenzar, monseñor, un capitulo fundamental que es la Universidad Católica Sedes Sapientiae. Escuché que si tuviese que bautizarla, le pondría la Divina Providencia, ¿por qué?

- Porque esa es otra aventura en la vida. En ciertos momentos, uno se pregunta: «¿Por qué me metí en esto?». Entonces, pienso y digo: «Porque el Señor quiso. Yo he querido muchas cosas, y lo que quise nunca se realizó». Lo último que pensé, desde que me nombraron obispo, fue hacer universidad; 
pensé en el seminario, en la catedral, en tantas cosas, menos en una universidad. La universidad fue la primera y la única obra de envergadura. Cuando comenzamos a dar respuesta a una necesidad, tuvimos muchísimas dificultades. Parecía que no funcionaría; sin embargo, cada dificultad siempre se superaba y se lograba avanzar. Cuando estábamos ya casi a punto de que nos dieran la autorización, nos dijeron: «La universidad tiene que tener local propio, no puede haber una universidad sin local».

Nosotros no teníamos nada, porque pensábamos hacer ahí un colegio. En eso le dije a Tista (Dr. Bolis): «Mira, Tista, nuestra aventura se acabó, porque no tenemos local». Estábamos en Roma, en el Vaticano. Luego regresé. Entonces me llamó un amigo y me dijo: «Lino, yo sé que tú buscas una casa, lo supe. Yo la tengo». Me dio el lugar donde está el Buen Pastor, el instituto. Le dije: «Pero yo no tengo plata para pagarte. ¿Cómo voy hacer?». Y me contestó: «Me la paga en 30 años; bueno, en 30 años poco a poco». Luego dimos la primera cuota y después no pudimos pagarla. Entonces dije: «Pedro, otra vez vamos a perder todo. Vamos a estar como la señora. Tenemos que hacer un préstamo». Estábamos en eso cuando me llamó un amigo y me dijo: «Sé que está en dificultades; le mando un cheque para pagar el préstamo». Así, se ve claramente uno de los muchos signos de la providencia.

- En la actualidad, ya tienen varias carreras, bastantes alumnos. Aparte de Educación y de Ciencias Económicas, tienen Ciencias de la Salud. Además, tienen maestría en Doctrina Social de la Iglesia Católica. En uno de los videos de cuando lo aprobó CONAFU, escuché una intervención que indicaba que el objetivo era que sirva para servir. ¿Cuál es el sueño de esta universidad? ¿Por qué el nombre Sedes Sapientiae? 
JOSÉ ANTONIO BENITO

-El nombre Sedes Sapientiae fue porque queríamos que fuese un lugar donde se encuentre la sabiduría, más que la ciencia. Sapientiae en latín es 'sabiduría', no es puro conocimiento. Creo que - y no es una crítica, es una observación mía - las universidades modernas forman grandes científicos, gente de conocimientos muy amplios, capaces de hacer máquinas o cosas por el estilo; pero, ¿¡forman hombres? Porque el hombre se forma a través de la sabiduría, no se forma a través de la ciencia. La ciencia puede llegar como hay ejemplos en la historia - a destruir a la humanidad, a destruirse a sí misma. Creo que en nuestro mundo, en nuestro Perú, se necesita hombres que realmente sean sabios, hombres justos en el sentido bíblico —como José, a quien en la Biblia llaman «hombre justo»—, hombres que realmente enseñan la verdad de la vida que Dios les da. Si uno no sirve a los demás, entonces su vida no tiene sentido. Creo que la razón de ser de los conocimientos, del crecimiento de la ciencia debe ser servir a los demás; ese es uno de los talentos que Dios le da a uno. Esto es un sueño, quizás un poco Don Quijote, pero es bonito. Sobre todo yo sueño de día y duermo de noche. Es bonito soñar un Perú justo y fraterno, un Perú donde los políticos y los administrativos no se sirvan de la gente, sino que sirvan a la gente. Ese es nuestro sueño: formar maestros cuya profesión no sea un trabajo, sino un servicio. Uno es maestro no para ganar dinero, uno es maestro para formar hombres; así como uno es economista para hacer que las riquezas se redistribuyan y que lleguen a todos, o como uno es enfermero para ayudar al enfermo a aceptar el sufrimiento o a superar el sufrimiento. Creo que la Universidad tiene que servir para esto, sino no sirve.

- El sueño, sin duda, lo está velando nuestro Dios y Santa María, aunque nosotros estemos durmiendo. Tenemos que hablar de muchisimas cosas. Toda la tarea de Caritas ha sido un rubro extraordinario a través del tiempo. Me 
gustaría, antes de terminar, saber qué nos puede decir sobre lo que está haciendo como Secretario de la Conferencia Episcopal. Se han reunido los obispos, ha habido notas escuetas. ¿Cuál es el programa para estos años? ¿Cómo están llevando a cabo lo de Aparecida? ¿Cuál ha sido su primer contacto con el trabajo de secretario?

—El primer contacto se produjo en estos días, porque la elección acaba de tener lugar. No tengo programa, porque no pensaba, no postulaba y no deseaba el nombramiento como Secretario General de la Conferencia Episcopal Peruana. Dios me lo ha pedido como un servicio y a Dios no se le puede decir no. Como decía al comienzo, haré lo mejor que pueda, dejando los resultados en las manos de Dios. Yo quiero simplemente — porque mis hermanos obispos me han pedido este servicio - hacerlo construyendo lo que quiero construir en mi Diócesis; es decir, lograr que seamos uno para que el mundo crea. Realmente, yo quisiera por mi vida y mi historia, una iglesia como mi Diócesis de comunión: donde todos se sienten en familia y donde nadie se siente excluido. Yo quiero una inclusión real. Que cada uno cumpla con lo que le corresponde. No hay derechos sin deberes. Nosotros estamos acostumbrados a reclamar; pero cuando hay que poner el hombro, a veces nos ponemos de lado. Quisiera solamente que nuestra iglesia sea la Iglesia que soñó Jesucristo: la iglesia en la que realmente el mundo cree porque ve nuestro amor. La iglesia de comunión es la que sueña el Concilio Vaticano II. La iglesia siempre es de comunión. La iglesia fue una. Es una de las características de la iglesia: una, santa, católica y apostólica de verdad; pero primero es «una». No hay dos iglesias, hay una sola. Esta unidad debe hacerse visible.

— ¿La Conferencia Episcopal ha tenido temas prioritarios y están trabajando enfocados, en este sentido, en la Misión Continental? 
JOSÉ ANTONIO BENITO

- Sí, el tema fundamental que hemos tomado en la asamblea fue casualmente la Misión Continental desde Aparecida, acatando la imitación de la V Conferencia General del Episcopado Latinoamericano, que lanza a la Iglesia a esta gran misión. Se ha hablado de esto. El problema es cómo será. De hecho va a ser lanzada oficialmente los primeros días de agosto por el Celam en el Cam. El Cam es el Congreso Americano de Misiones que se realiza junto con el Celam, allí será lanzada la apertura de la Misión Continental. Después, cada país y cada diócesis se organiza para ver cómo llevarlo adelante; de hecho es un desafío para toda la iglesia, para los obispos, los sacerdotes, los religiosos, las personas consagradas y para los laicos de pie. Para todos realmente — como decía el poeta— hay mucho que hacer.

-Monseñor, una última pregunta. Usted comentó en algún momento que ahi, en la parroquia de Chama, realizó su pachamanca cuando vinieron los obispos para preparar el centenario de Santo Toribio y los 50 años del CELAM. También organizó una pachamanca en el Santuario de Quives, en su Diócesis, que fue un encuentro de santos, ¿qué le sugiere este encuentro de santos, Santa Rosa y Santo Toribio, para despedir este programa?

-Apenas fue fundada la diócesis, lancé una idea: «Tenemos los santos más grandes, en todo sentido, de América y de la iglesia: Santo Toribio y Santa Rosa». Yo tengo la gracia de que hayan estado los dos en la diócesis; entonces quise unir esos dos santos simbólicamente en un camino que tiene que hacer la diócesis; por eso, todas las parroquias nos reunimos en la plaza de San Pedro de Carabayllo de la iglesia del 1500, y de allí fuimos peregrinando hacia Quives a pie durante un día y una noche caminando. Así hicimos el peregrinaje. Éramos como 5000 o 6000 personas, y ahí celebramos la acción de gracias al Señor por el don que nos había dado sobre esta nueva porción de la Iglesia. Para el año del jubileo toribiano, invité a los 
obispos. También nosotros debimos hacer la peregrinación a su santuario. Para adquirir la indulgencia plenaria, había que ir a un santuario. Entonces pregunté: «¿Por qué no vamos a Quives?» Santa Rosa es patrona del Perú y de Lima, de América; es bonito que todos los obispos vayamos, nos reconciliemos, celebremos la eucaristía y compartamos, y así fuimos. Aquí también caminamos y nos confesamos y celebramos la eucaristía. Luego había llamado a unos amigos, a familias amigas de Huánuco y de Huaraz para que me prepararan una pachamanca y terminamos con la pachamanca para celebrar el jubileo después de haber recibido la reconciliación, la eucaristía y la indulgencia.

-Y en la compañia de los dos grandes santos, y donde Santo Toribio confirmó a Santa Rosa.

Donde confirmamos nuestra fe como pastores de la Iglesia.

-Monseñor, muchisimas gracias, ya se nos fue el tiempo. Nos gustaría que, para todos los televidentes y para las personas que lo queremos y le tenemos tanto que agradecer, nos dé la bendición.

— Realmente estamos agradecidos al Señor por el amor que nos tiene y por la bondad que manifiesta a cada uno de nosotros. Yo quisiera que cada uno supiera y aprendiera a descubrir el amor de Dios, el que le tiene a cada uno de los televidentes. Para todos ellos: el Señor los bendiga en el nombre del Padre, del Hijo y del Espíritu Santo. Amén.

Muchas gracias. 